\title{
CORE-SHELL MICROPARTICLE SYNTHESIS IN DROPLET MICROFLUIDICS USING A SINGLE STEP POLYMERIZATION
}

\author{
Xiamo Zhou, Yang Sun, Anna Finne-Wistrand, Wouter van der Wijngaart* and Tommy Haraldsson \\ KTH Royal Institute of Technology, Stockholm, SWEDEN
}

\begin{abstract}
We present, for the first time, a method for the synthesis of core-shell microparticles in a single polymerization step using two-phase droplet microfluidics. We verify the successful generation of core-shell microparticles using the novel synthesis approach. To enable (future) cell encapsulation, this novel method is specifically designed to allow: i) uncomplicated synthesis of core-shell microparticles and ii) well-controlled and reproducible shell thickness with a perfectly centred core.
\end{abstract}

\section{INTRODUCTION}

Core-shell polymer structures have been proposed and investigated since 1961 [1], and have been used in a large scale in applications such as impact modifiers, surface coating, catalysis, sensing and drug delivery [2]-[4]. A core-shell structure usually has at least two different components, constituting the core and the shell of the particles respectively, in which the core-shell composite expresses superior properties not possessed by any of the single component [5].

\section{Two stage emulsion polymerization}

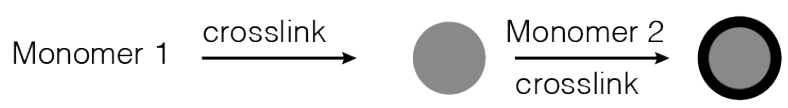

2. Emulsion polymerization with reactive surfactant

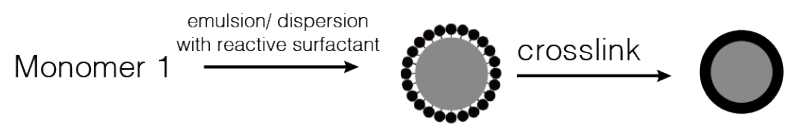

3. Step-wise hetero-coagulation

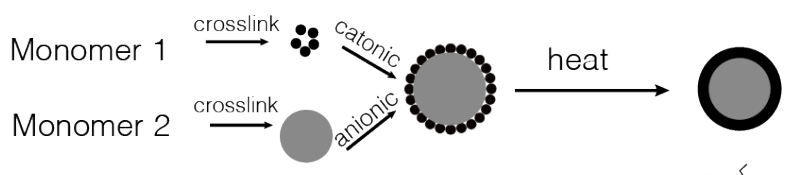

\section{Block copolymerization}

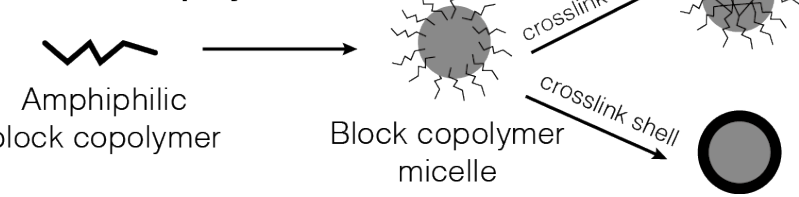

Figure 1: Illustration of previous methods for core-shell structure preparation.

Traditional core-shell micro/nano particle synthesis methods include dispersion, suspension, emulsion and combined polymerization ranging from a single step to multiple steps [5], [6]. The most common methods are two-stage emulsion polymerization, reactive surfactant emulsion polymerization, step-wise hetero-coagulation and block copolymerization (Fig. 1). Previous core-shell particle manufacturing techniques using capillary microfluidic based emulsion can be classified in two approaches (Fig. 2). In the two-step polymerization approach, the core is first created and a shell is added subsequently, which imparts complexity and cost. The three-phase double emulsion approach creates a good size uniformity but results in poorly controlled core-shell morphology where the core is easily displaced from the centre, the shell has varying thickness, and/or the core-shell morphology varies from batch to batch due to difficulty in controlling three phase systems [7], [8].

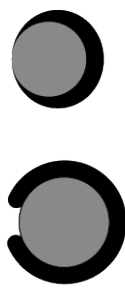

Two step or double emulsion polymerization gives a "moon-like" structure

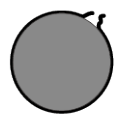

External stimuli can cause core swelling thus break the shell coating

Thin shell structure is impossible to achieve: shear force in emulsion polymerization is too high to maintain the thin shell formation.

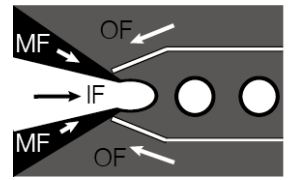

Three-phase double emulsion is hard to control, resulting in a shell structure with ill-defined core placement and shell thickness.

Figure 2: Illustration of problems inherent to previous droplet microfluidic core-shell microparticle synthesis methods.

\section{NOVEL CONCEPT}

Here, we present a novel and uncomplicated, microfluidics based particle synthesis platform as a promising solution for generating precisely controlled core-shell geometries (Fig. 3). Our platform features microdroplet generation of a disperse droplet phase into a continuous phase, followed by a UV exposure that simultaneously crosslinks the droplets and grafts a surrounding shell. The dispersed phase consists of water dissolved hydrogel monomer (PEGDA) and photoinitiator (Irgacure 2959). The continuous phase consists of shell components (GPTA) and surfactant (Span 80) dissolved in toluene. The UV exposure creates radicals from initiators and polymerizes the PEGDA droplet, during which the core radicals diffuse to the droplet interface, where they trigger the polymerization of the GPTA shell in a grafting from fashion. The result of this simultaneous PEGDA core and GPTA shell polymerization is particles with an evenly distributed, well-defined shell, generated at a fairly high synthesis speed of up to 400 particles/min. 


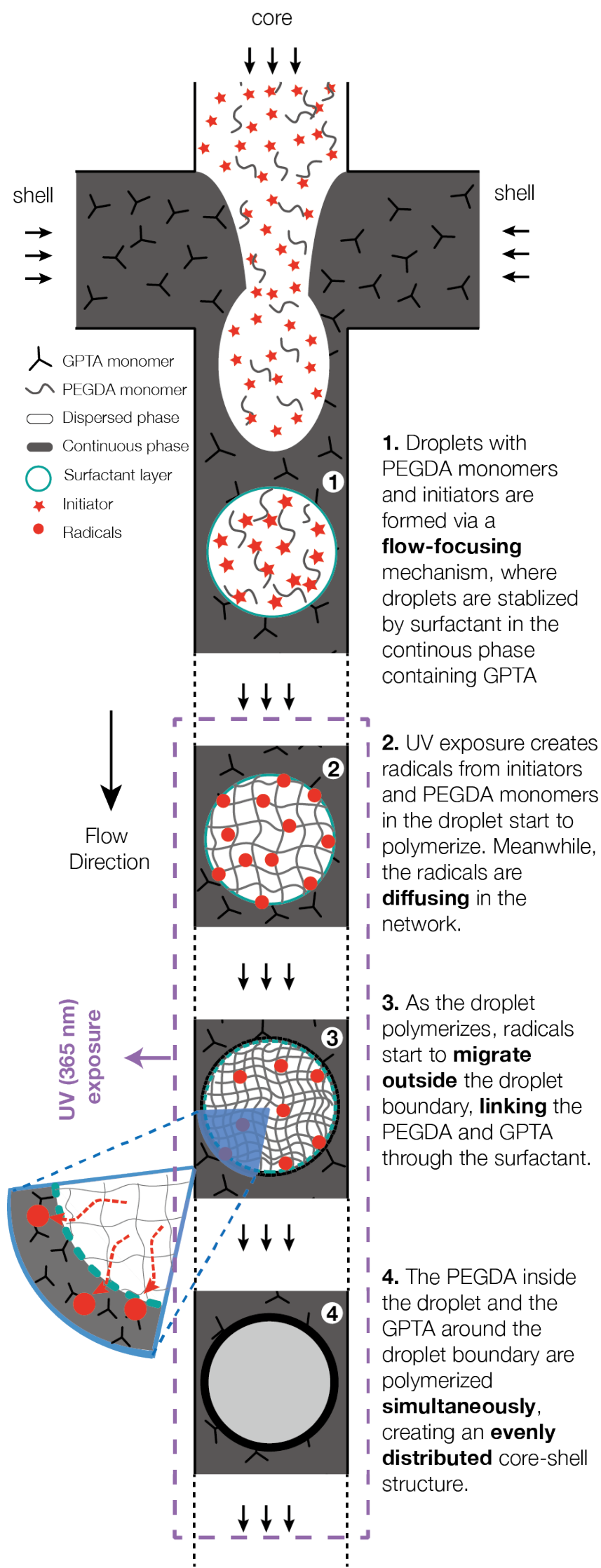

Figure 3: Illustration of our novel approach: one step core-shell polymer synthesis mechanism.

\section{EXPERIMENTAL}

The microfluidic synthesis platform consists of a $75 \mathrm{x}$ $25 \mathrm{~mm}^{2}$ microfluidic chip made of off-stoichiometry thiol-ene-epoxy polymer (OSTE+ 50\%, Mercene Labs AB, Sweden, cured by OAI Model 30 Collimated UV Light Source, USA) placed underneath a UV station (Fig. 4; UV LED 365nm, 10W, KT-electronic, Germany). The two inlets of the chip are connected to syringe pumps (NE-1000, New Era Pump Systems, Inc. NY, USA) using PEEK tubing (1/32', OD, Mengel Engineering, USA) and corresponding NanoPort ${ }^{\mathrm{TM}}$ Assemblies (N-126S, Upchurch Scientific, IDEX Health \& Science LLC). The syringe for the continuous phase solution is loaded with $30 \% \mathrm{w} / \mathrm{w}$ glycerol propoxylate triacrylate (GPTA, Sigma-Aldrich, Sweden) and 0.5\% w/w Span 80 (Sigma -Aldrich, Sweden) dissolved in toluene (Sigma-Aldrich, Sweden), and the syringe for dispersed phase is loaded with water solution containing $25 \% \mathrm{w} / \mathrm{w}$ poly(ethylene glycol) diacrylate (PEGDA, MW $=6 \mathrm{kDa}$, Sigma-Aldrich, Sweden) as hydrogel monomer, and $0.5 \% \mathrm{w} / \mathrm{w}$ 2-Hydroxy-4'-(2-hydroxyethoxy)-2-methylpropiophenone (Irgacure 2959, Sigma-Aldrich, Sweden) as photoinitiator. A collecting vessel is connected to the outlet of the chip by PTFE tubing.

The microfluidic device concatenates a droplet generating channel junction with a polymerization section, which consists of a $600 \mathrm{~mm}$ long meandering channel (Fig. 4).

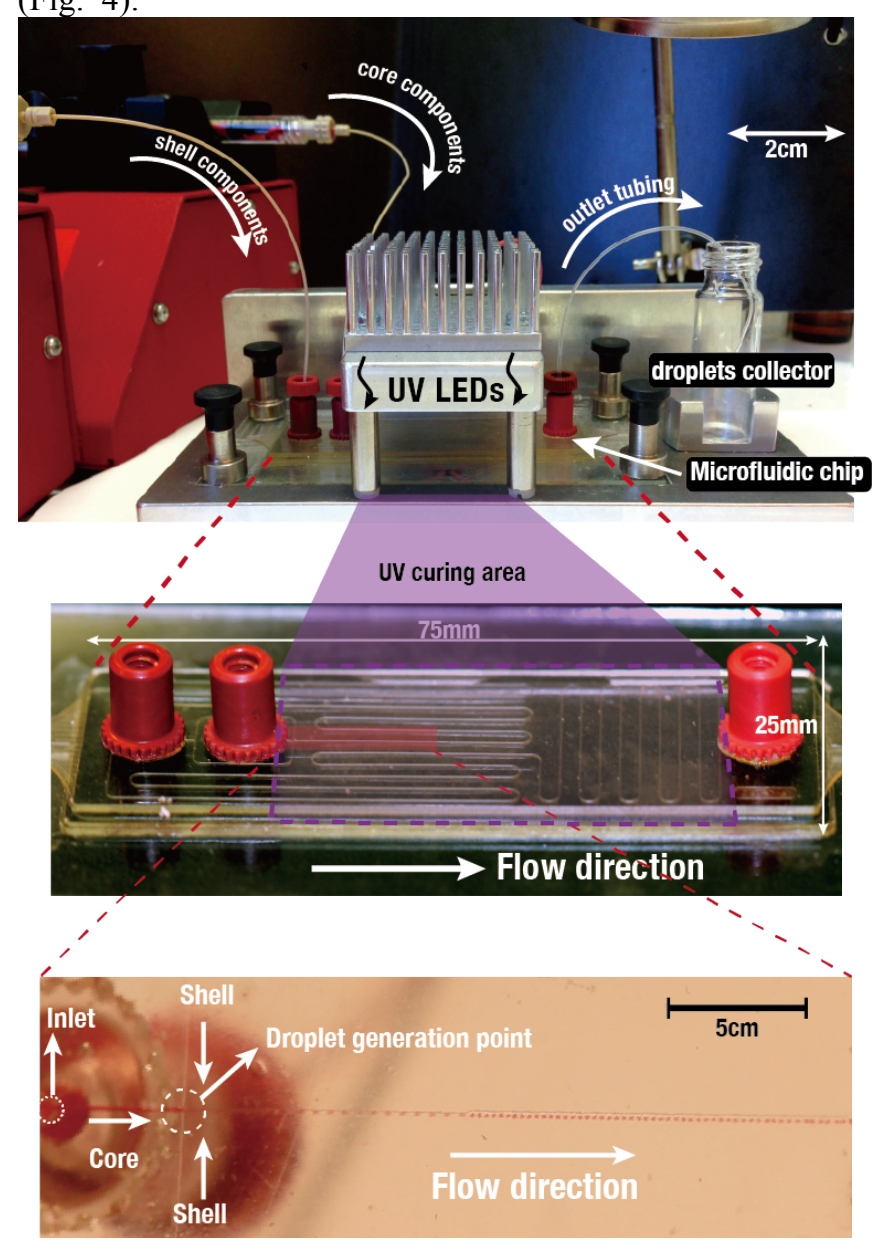

Figure 4: UV station setup for core-shell synthesis (upper); the microfluidic chip with long meander channels for core-shell particle preparation (middle); the droplets (red dyed) generated from flow-focusing microfluidic chip at the speed of $\sim 400$ particles/min. The droplets diameter is $\sim 100 \mu \mathrm{m}$ (lower). 
We performed three experiments. Experiment A was designed to generate core-shell microparticles with the above described synthesis method. Control experiments $\mathrm{B} \& \mathrm{C}$ were designed to investigate the diffusion barrier function of the polymerized shell. In both experiments B and $\mathrm{C}$, the PEGDA in the dispersed phase was substituted with polyethylene glycol (PEG, Sigma-Aldrich, Sweden), which has no functional groups for photo crosslinking and which is thus expected to remain in its liquid state during UV exposure. The photo-initiator (Irgacure 2959) is absent in the dispersed phase in experiment $\mathrm{B}$, while present in experiment $\mathrm{C}$ (see Table 1). Hence, we expect shell polymerization only in experiment $C$. Red food dye was added to all dispersed phases for visualisation.

\section{RESULTS}

Experiment A successfully generated core-shell particles (Table 1, A). A polymerized core-shell polymer structure collected from the outlet tubing shows a homogenous whitish shell around a red dyed PEGDA core, indicating a well-polymerized structure. The elongated shape is attributed to the hydrodynamic forces during polymerization.

Control experiment $B$ resulted in a stream of dissolved red-dyed PEG emanating from the droplet. The lack of photoinitiator in the PEG core prevents formation of a polymerized protective shell. Once in contact with water in the collection vessel, the droplet rapidly disintegrates.

Control experiment $\mathrm{C}$ resulted in a batch of coloured beads in the collection vessel. This indicates the presence of a polymerized shell which protects the un-corsslinked liquid core from the water in the collection vessel.

The difference between $\mathrm{B}$ and $\mathrm{C}$ can only be attributed to the successful formation of a shell in $\mathrm{C}$ and the absence of such shell in B.

\section{CONCLUSIONS}

We have demonstrated a single step polymerization method to prepare size-controlled and uniformly distributed core-shell microparticles in a microfluidic device. The polymerization mechanism is initiated by radical diffusion from the core components towards the core-shell boundary, thus polymerizing a homogenous thin shell around the core as well as crosslinking the core and shell polymers simultaneously. We also verify the existence of the surrounding shell by substituting the core monomer with a non-crosslinkable monomer, from which the experimental group with the presence of photoinitiator formed a shell and maintain the droplet shape while the one with the absence of photoinitiator lysis to water.

\section{ACKNOWLEDGEMENTS}

We gratefully acknowledge the financial support by Barncancerfonden, Sweden. We also express our gratitude to Mercene Labs AB for providing the OSTE+ polymers.
Table 1: Experimental results of core-shell particle formation $(A)$ and control experiments $(B \& C)$ to verify the existence of the shell.

\begin{tabular}{|c|c|}
\hline $\begin{array}{l}\text { EXPERIMENT } \\
\qquad \text {-A- } \\
\text { Fully polymerized } \\
\text { core-shell particle }\end{array}$ & $\overline{100 \mu \mathrm{m}}$ \\
\hline $\begin{array}{c}\text { Dispersed phase } \\
\text { components }\end{array}$ & $\begin{array}{c}\text { DI water } \\
\text { PEGDA }(25 \% \mathrm{w} / \mathrm{w}) \\
\text { Irgacure } 2959 \text { initiator }(0.1 \% \mathrm{w} / \mathrm{w}) \\
\text { Red dye }\end{array}$ \\
\hline $\begin{array}{c}\text { Continuous phase } \\
\text { components }\end{array}$ & $\begin{array}{c}\text { Toluene } \\
\text { GPTA }(30 \% \mathrm{w} / \mathrm{w}) \\
\text { Span } 80 \text { surfactant }(0.5 \% \mathrm{w} / \mathrm{w})\end{array}$ \\
\hline $\begin{array}{c}\text { Phenomenon } \\
\text { observed }\end{array}$ & $\begin{array}{l}\text { A homogenous white shell around } \\
\text { a red core, the elliptical shape is } \\
\text { created by hydrodynamic force and } \\
\text { well preserved by polymerization. } \\
\text { (Picture taken from collection } \\
\text { tubing) }\end{array}$ \\
\hline $\begin{array}{c}\text { EXPERIMENT } \\
\text {-B- } \\
\text { Unpolymerized } \\
\text { PEG without shell } \\
\text { results in PEG } \\
\text { droplets that } \\
\text { dissolve in water }\end{array}$ & $\begin{array}{l}\stackrel{2 \mathrm{~mm}}{\text { Dissovled PEG }} \\
\text { red dye trail }\end{array}$ \\
\hline $\begin{array}{l}\text { Dispersed phase } \\
\text { components }\end{array}$ & $\begin{array}{c}\text { DI water } \\
\text { PEG monomer }(25 \% \mathrm{w} / \mathrm{w}) \\
\text { Red dye }\end{array}$ \\
\hline
\end{tabular}




\begin{tabular}{|c|c|}
\hline $\begin{array}{l}\text { Continuous phase } \\
\text { components }\end{array}$ & $\begin{array}{c}\text { Toluene } \\
\text { GPTA }(30 \% \mathrm{w} / \mathrm{w}) \\
\text { Span } 80 \text { surfactant }(0.5 \% \mathrm{w} / \mathrm{w})\end{array}$ \\
\hline $\begin{array}{c}\text { Phenomenon } \\
\text { observed }\end{array}$ & $\begin{array}{l}\text { Unpolymerized hydrophilic core } \\
\text { with no shell due to the absence of } \\
\text { initiator in the core component } \\
\text { results in PEG lysis into water } \\
\text { instantly. }\end{array}$ \\
\hline $\begin{array}{l}\text { EXPERIMENT } \\
\text {-C- } \\
\text { Un-crosslinked } \\
\text { PEG with shell } \\
\text { results in stably } \\
\text { encapsulated PEG } \\
\text { droplets }\end{array}$ & $\stackrel{\text { Red particles }}{\stackrel{2 \mathrm{~mm}}{\longrightarrow}}$ \\
\hline $\begin{array}{c}\text { Dispersed phase } \\
\text { components }\end{array}$ & $\begin{array}{c}\text { DI water } \\
\text { PEG monomer }(25 \% \mathrm{w} / \mathrm{w}) \\
\text { Irgacure } 2959 \text { initiator }(0.1 \% \mathrm{w} / \mathrm{w}) \\
\text { Red dye }\end{array}$ \\
\hline $\begin{array}{l}\text { Continuous phase } \\
\text { components }\end{array}$ & $\begin{array}{c}\text { Toluene } \\
\text { GPTA }(30 \% \mathrm{w} / \mathrm{w}) \\
\text { Span } 80 \text { surfactant }(0.5 \% \mathrm{w} / \mathrm{w})\end{array}$ \\
\hline $\begin{array}{c}\text { Phenomenon } \\
\text { observed }\end{array}$ & $\begin{array}{l}\text { Un-crosslinked hydrophilic core } \\
\text { with a polymerized shell due to the } \\
\text { migration of initiator in the core } \\
\text { component maintains its shape in } \\
\text { water for a while. Hence, a shell } \\
\text { exists. }\end{array}$ \\
\hline
\end{tabular}

\section{REFERENCES}

[1] L. J. Hughes and G. L. Brown, "Heterogeneous polymer systems. I. Torsional modulus studies," Journal of Applied Polymer Science, vol. 5, no. 17, pp. 580-588, Sep. 1961.
[2] A. K. Khan, B. C. Ray, J. Maiti, and S. K. Dolui, "Preparation of core-shell latex from co-polymer of styrene-butyl acrylate-methyl methacrylate and their paint properties: Pigment \& Resin Technology: Vol 38, No 3," Pigment \& Resin Technology, vol. 38, no. 3, pp. 159-164, 2009.

[3] C. D. J. and and L. A. Lyon, "Shell-Restricted Swelling and Core Compression in Poly(N-isopropylacrylamide) Core-Shell Microgels," Macromolecules, vol. 36, no. 6, pp. 1988-1993, Feb. 2003.

[4] W.-H. L. and H. D. H. Stöver, "Monodisperse Cross-Linked Core-Shell Polymer Microspheres by Precipitation Polymerization," Macromolecules, vol. 33, no. 12, pp. 4354-4360, Jun. 2000.

[5] H. JW, P. IJ, L. SB, and K. DK, "Preparation and characterization of core-shell particles containing perfluoroalkyl acrylate in the shell," Macromolecules, vol. 35, no. 18, pp. 6811-6818, 2002.

[6] M. Jonsson, O. Nordin, E. Malmström, and C. Hammer, "Suspension polymerization of thermally expandable core/shell particles," Polymer, vol. 47, no. 10, pp. 3315-3324, May 2006.

[7] Y.-L. Yu, R. Xie, M.-J. Zhang, P.-F. Li, L. Yang, X.-J. Ju, and L.-Y. Chu, "Monodisperse microspheres with poly(N-isopropylacrylamide) core and poly(2-hydroxyethyl methacrylate) shell," Journal of Colloid and Interface Science, vol. 346, no. 2, pp. 361-369, Jun. 2010.

[8] J.-W. Kim, A. S. Utada, A. Fernández-Nieves, Z. $\mathrm{Hu}$, and D. A. Weitz, "Fabrication of Monodisperse Gel Shells and Functional Microgels in Microfluidic Devices," Angewandte Chemie International Edition, vol. 46, no. 11, pp. 1819-1822, Mar. 2007.

\section{CONTACT}

*Wouter van der Wijngaart

Tel:+4687906613

E-mail: wouter@kth.se 